\title{
Perancangan Sistem Informasi POS (Point Of Sales) Berbasis Web dengan Menggunakan Framework Codeigniter pada Pasar Swalayan
}

\author{
Muhammad Galang Ramadhan ${ }^{1}$, Lela Nurpulaela ${ }^{2}$, Ulinnuha Latifa ${ }^{3}$ \\ ${ }^{123}$ Jurusan Teknik Elektro Universitas Singaperbangsa, Karawang \\ Jl. HS. Ronggo Waluyo, Puseurjaya, Kec. Telukjambe Timur, \\ Kabupaten Karawang, Jawa Barat 41361 \\ ${ }^{1}$ muhammad.galangr16089@student.unsika.ac.id \\ ${ }^{2}$ lela.nurpulaeladft.unsika.ac.id \\ ${ }^{3} u l i n n u h a . l a t i f a @ f t . u n s i k a \cdot a c \cdot i d$
}

Intisari - Perkembangan pasar swalayan belakangan ini berkembang sangat pesat. Hampir disetiap perumahan ter-dapat berbagai minimarket-minimarket berbasis waralaba seperti Indomaret, Alfamart, dan pengusaha menengah. Begitupun sistem pengolahan data pada pengusaha menengah yang rata-rata masih menggunakan sistem manual atau dicatat, dapat mengakibatkan kesalahan pada pengolahan laporan penjualan, dan keluar masuknya barang. Tujuan dari penelitian ini adalah memberikan solusi kepada pengusaha pasar swalayan dalam hal pengolahan data dan merancang sistem informasi Point of Sales yang mudah dioperasikan oleh pengguna. Penelitian ini dilaksanakan selama 6 bulan di pasar swalayan daerah Kabupaten Karawang. Model pengembangan sistem yang dipakai dalam penelitian ini adalah model Waterfall, inti dari metode Waterfall adalah pengerjaan dari suatu sistem dilakukan secara berurutan atau secara linear, metode ini memiliki beberapa tahapan yaitu analisis kebutuhan, desain, coding, pengujian dan implementasi. Setelah melakukan analisis kebutuhan, maka dirancanglah sistem POS dengan menggunakan Framework CodeIgniter untuk membangun aplikasi PHP yang dinamis, serta menggunakan XAMPP sebagai server (localhost). Hasil dari penelitian yang telah dirancang pada sistem POS berupa print nota belanja. Respon Sangat Setuju (SS) memiliki frekuensi 24 respon dan persentase yang didapat sebesar $21,82 \%$. Respon Setuju (S) memiliki frekuensi 63 respon dan persentase yang didapat sebesar 57,27\%. Respon Netral (N) memiliki 23 respon dan persentase sebesar $\mathbf{2 0 , 9 1 \%}$. Sedangkan respon Tidak Setuju (TS) dan Sangat Tidak Setuju (STS) sama sekali tidak memiliki respon.

Kata kunci — : Point of Sales (POS), PHP, WEB.

Abstract - The development of supermarkets lately is developing very rapidly. In almost every housing there are various franchise-based minimarkets such as Indomaret, Alfamart, and medium-sized entrepreneurs. Likewise, the data processing system of medium-sized entrepreneurs who on average still use manual or recorded systems, can result in errors in processing sales reports, and the entry and exit of goods. The purpose of this research is to provide solutions to supermarket entrepreneurs in terms of data processing and designing a Point of Sale in-formation system that is easy to operate by users. This research was conducted for 6 months in supermarkets in the Karawang regency. The system development model used in this study is the Waterfall model, the core of the Waterfall method is that the workmanship of a system is carried out sequentially or linearly, this method has several stages namely needs analysis, design, coding, testing and implementation. After conducting a needs analysis, the POS system was designed using the CodeIgniter Framework to build dynamic PHP applications, as well as using XAMPP as a server (localhost). The results of the research that has been designed on the POS system in the form of a shopping note print. 7. Sangat Setuju (SS) has a frequency of 24 responses and the per-centage obtained is $21.82 \%$. Setuju $(S)$ has a frequency of 63 responses and the percentage obtained is $57.27 \%$. Netral $(\mathrm{N})$ has 23 responses and a percentage of $20.91 \%$. While the response Tidak Setuju (TS) and Sangat Tidak Setuju (STS) has no response at all.

Keywords - Point of Sales (POS), PHP, WEB 


\section{PENDAHULUAN}

Perkembangan pasar swalayan belakangan ini berkembang sangat pesat. Hampir disetiap perumahan terdapat berbagai pasar swalayan berbasis waralaba seperti Indomaret, Alfamart, dan pengusaha menengah. Hal ini membuat persaingan semakin ketat dikarenakan konsumen mempunyai banyak alternatif pilihan berbelanja atau dapat dikatakan sulit dalam menentukan keputusan pembelian. Untuk meningkatkan penjualan maka produsen menentukan strategi pemasaran yang tepat, agar mampu bersaing dengan perusahaan lain yang memproduksi barang yang sama.

Dalam dunia usaha, proses penjualan adalah suatu proses yang sangat vital yang menentukan siklus hidup kelangsungan perusahaan. Sistem Informasi adalah kumpulan elemen yang saling berhubungan dan berfungsi untuk memproses, mengumpulkan, mendistribusikan serta menyimpan informasi yang berguna sebagai pendukung dalam pembuatan keputusan juga pengawasan dalam organisasi [1]. Karena frekuensi pembeli yang meningkat sehingga mengakibatkan antrian pada saat melakukan transaksi penjualan, maka dari itu penyediaan sistem informasi yang dapat mendukung dan meningkatkan proses penjualan sangatlah dibutuhkan.

Sistem Point of Sales (POS) adalah sebuah sistem aplikasi yang diterapkan pada bisnis minimarket ataupun pertokoan untuk menangani pengolahan data transaksi pembelian (purchases), transaksi penjualan eceran (retails), transaksi hutang (liabilities), transaksi retur pembelian (purchase returns), dan pelaporan transaksi (reporting) yangsecara umum penting dibutuhkan dalam pengambilan keputusan strategik oleh para pebisnis swalayan, organisasi, atau perusahaan yang berskala kecil dan menengah [2]. Perusahaan besar maupun perusahaan menengah yang bergerak di dalam bidang perdagangan, pada umumnya akan menggunakan sistem POS dalam menunjang kegiatan usahanya.

Hampir seluruh pasar swalayan pada daerah Karawang menggunakan sistem informasi Point of Sales untuk mendukung dan mengelola proses penjualan pada usahanya masing-masing. Hanya saja untuk pengusaha skala menengah masih menggunakan penjualan dengan sistem manual. Proses transaksi yang masih menggunakan metode manual, tanpa memakai alat bantu berupa sistem akuntansi atau perhitungan yang otomatis, sehingga memperlambat dalam proses transaksi pembayaran. Tidak hanya proses transaksi yang menjadi lambat, pengolahan data untuk laporan pemasukan dan pengeluaran pun masih menggunakan metode manual. Hal ini mengakibatkan peluang kesalahan dalam input data laporan semakin besar, karena pemilik toko masih mencatat pada kertas untuk laporan penjualannya. Selain itu, bukti pembayaran atau nota masih dilakukan dengan mencatat hasil pembayaran kepada pelanggan yang sedang berbelanja. Kegiatan tersebut akan memakan waktu yang lama. Permasalahan-permasalahan tersebut akan mengakibatkan antrian bila terdapat banyak pelanggan yang sedang berbelanja pada toko.

Tujuan dilakukan pembuatan aplikasi Point of Sales pada penelitian ini adalah untuk mengatasi sistem pendataan atau pengolahan data barang yang masuk maupun yang keluar agar terhindar dari kesalahan (human error), merancang sistem aplikasi Point of Sales yang mudah dioperasikan oleh pengguna dengan membagi sistem menjadi 2 bagian Admin dan Kasir agar lebih efisien dalam tugasnya masing-masing.

Manfaat dari sistem Point of Sales untuk sebuah organisasi salah satunya adalah untuk mengolah transaksi-transaksi, mengurangi biaya dan menghasilkan pendapatan sebagai salah satu produk atau pelayanan mereka. Perusahaan menggunakan sistem Point of Sale untuk mempertahankan persediaan pada tingkat paling rendah agar konsisten dengan jenis barang yang tersedia [3].

Berdasarkan latar belakang masalah pada penelitian ini, maka dirancanglah suatu sistem layanan informasi POS (Point of Sales) berbasis web dengan menggunakan framework codeigniter yang terkomputerisasi, guna mempermudah pengusaha. 


\section{STUDI LITERATUR}

Silvester [4], dengan judul penelitian "Analisa dan Perancangan Aplikasi Point of Sales (POS) untuk Mendukung Manajemen Hubungan Pelanggan", menjelaskan rancangan aplikasi POS ini mampu mengatasi permasaahan dan dapat menyajikan informasi secara lebih baik dan terkomputerisasi.

Diterapkannya aplikasi POS ini dapat membantu tugas pihak-pihak terkait atau stakeholder yang berhubungan langsung dengan aplikasi POS ini. Aplikasi POS ini didesain dengan antar muka interaktif sehingga baik administasi maupun pemilik dapat langsung menggunakan aplikasi POS ini dengan sebaik-baiknya. Perancangan sistem yang digunakan pada penelitian ini dengan menggunakan diagram berbasis obyek dengan alat bantu peracangan aplikasi berupa diagram alir/ flowchart dan Unified Modeling Language (UML) yaitu berupa Use Case Diagaram, Class Diagram, Activity Diagram dan Sequence Diagram.

Jodhi [5], dalam penelitian "Pembuatan Aplikasi Point of Sales Toko Cabang Perusahaan Torani Menggunakan Framework CodeIgniter", menjelaskan aplikasi Point of Sales ini dibuat untuk meminimalisasi pendataan barang dan transaksi secara manual serta penggunaan telepon untuk melakukan pemesanan terhadap distributor. Manfaat dari sistem Point of Sales untuk sebuah organisasi salah satunya adalah untuk mengolah transaksi-transaksi, mengurangi biaya dan menghasilkan pendapatan sebagai salah satu produk atau pelayanan mereka. Perusahaan menggunakan sistem Point of Sales untuk mempertahankan persediaan pada tingkat paling rendah agar konsistem dengan jenis barang yang tersedia.

Rahayu [6], dalam penelitian "Aplikasi Point of Sale Berbasis Web Menggunakan Framework CodeIgnitier pada Martabak ABC" menjelaskan bahwa menghasilkan suatu aplikasi yang ber-manfaat serta memberikan kemudahan kepada Martabak $\mathrm{ABC}$ dalam pengolahan data dan mengetahui laporan penjualan secara cepat dan akurat, serta mempermudah kasir dalam pelayanan transaksi penjualan. Perancangan tabel database yang digambarkan dengan Entity Relationship Diagram (ERD) berdasarkan data-data yang diperoleh pada tahap sebelumnya.

\section{METODOLOGI PENELITIAN}

\section{A. Waktu dan Tempat Penelitian}

Waktu penelitian ini dilaksanakan selama 6 bulan dari bulan Januari hingga bulan Juni 2020. Penelitian dilakukan pada pasar swalayan dan pengusaha kelas menengah yang berada di daerah Karawang.

\section{B. Metode Sistem}

Model pengembangan sistem yang dipakai dalam penelitian ini adalah model Waterfall. Metode ini merupakan metode yang sering digunakan oleh penganalisa sistem pada umumnya. Metode Waterfall adalah model yang paling banyak digunakan untuk tahap pengembangan. Model Waterfall ini juga dikenal dengan nama model tradisional atau model klasik. Model air terjun (Waterfall) sering juga disebut model sekuensial linier (Squential Linear) atau alur hidup klasik (Classic Cycle)". Model air terjun ini menyediakan pendekatan alur hidup perangkat lunak secara sekuensial terurut dimulai dari analisis, desain, pengkodean, pengujian dan tahap pendukung (Support) [7]. Jadi jika langkah satu belum dikerjakan maka tidak akan bisa melakukan pengerjaan langkah 2, 3 dan seterusnya. Secara otomatis tahapan ke-3 akan bisa dil-akukan jika tahap ke-1 dan ke-2 sudah dilakukan. Berikut penjelasan Metode Sistem Waterfall pada penelitian ini:

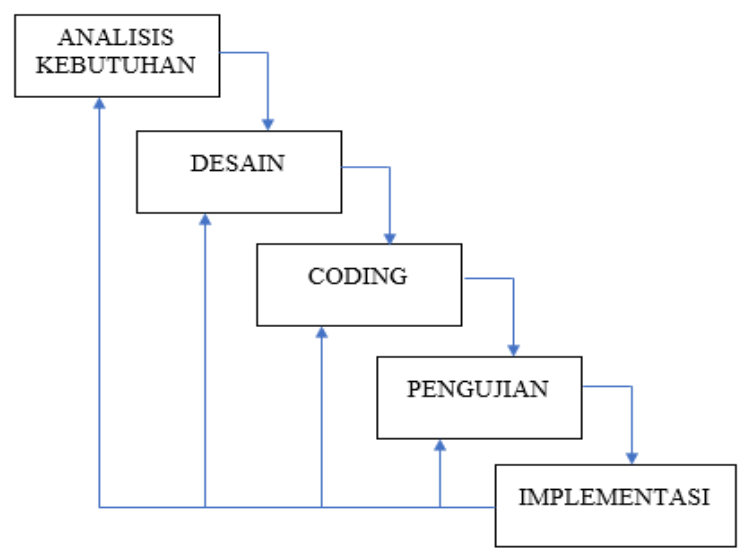

Gbr. 1 Metode Waterfall 
Tahap Pendahuluan, pertama kali sistematika pemecahan masalah dimulai dengan tahap pen-dahuluan. Tahap pendahuluan dimulai dengan menemukan masalah, menentukan tujuan dan manfaat, mengumpulkan data serta mempelajari studi pustaka dan studi lapangan untuk menyelesaikan permasalahan yang telah dikerjakan. Tahap Analisis, Tahap kedua pada sistematika pemecahan masalah adalah tahap analisis, di-mana pada proses ini semua data yang telah didapat dan terdokumentasi akan diolah. Tahap analisis dimlulai dengan menganalisis semua kemungkinan yang akan terjadi serta masalah yang terjadi di objek penelitian.

Tahap Desain, pada tahap ini adalah tahap dimana perancangan seluruh sistem yang akan dibangun. Tahap perancangan meliputi perancangan basis data, antar muka, dan perancangan sistem dengan menggunakan MySQL. Perancangan basis data diperlukan untuk mengatur relasi antar data yang akan ada di sistem dan penggunaannya sesuai algoritma yang akan dibangun. Tahap Coding, tahap coding adalah tahap dimana setelah urutan proses analisa dan perancangann telah selesai dikerjakan. Tahap coding yaitu tahap pembuatan kode algoritma atau kode logic dari seluruh program yang dibangun dengan menggunakan bahasa program PHP.

Tahap Pengujian, pada tahap ini dilakukan pengujian sistem Point of Sales yang dihubungkan langsung dengan barcode scanner melalui arduino uno.Tahap Implementasi, tahap implementasi yaitu tahap setelah sistem selesai diuji dan siap untuk dipakai oleh objek penelitian sesuai dengan analisa teknologi yang akan dipakai.

\section{Diagram Alir POS}

Mengawali sistem aplikasi POS ini dengan login terlebih dahulu pada halaman web login. Setelah login, masuk ke menu transaction lalu sale, untuk menerima data barang dari alat yang telah di scan oleh scanner barcode. Kemudian melakukan proses transaksi pada menu sale, lalu bila telah setuju dengan barang yang ingin dibeli maka sistem akan menyimpan data ke database. Daftar belanjaan yang telah dibeli, akan dicetak melalui printer yang telah tersedia.

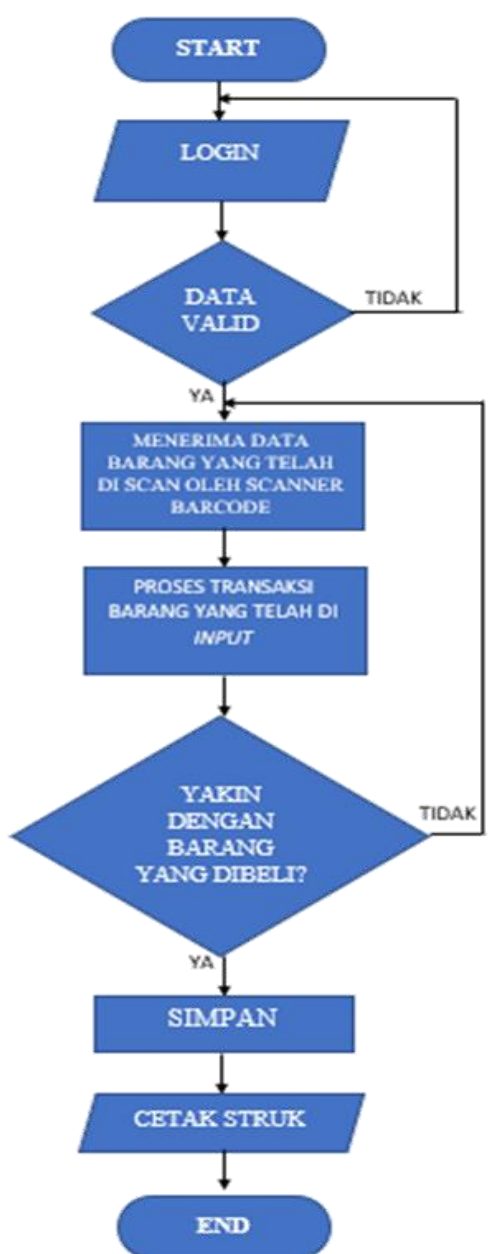

Gbr. 2 Diagram Alir POS

\section{HASIL DAN PEMBAHASAN}

Sistem POS ini dirancang untuk supermarket atau pasar swalayan yang berada di Karawang. Pada sistem ini terdapat dua pengguna (User) antara lain Admin dan Kasir. Admin dalam sistem ini bertugas untuk input data supplier, data pelanggan (Customer), mengelola stok yang masuk ke POS dari supplier, mengelola data pengguna (User), dan mengelola data barang. Kasir pada sistem ini bertugas memasukkan data kategori barang yang tersedia, data satuan barang, melakukan transaksi dengan pelanggan, dan melakukan pencetakkan struk atau nota belanjaan. Pengguna admin pada sistem ini juga dapat mengakses semua yang ada pada sistem POS ini.

\section{A. Tampilan Halaman Login}

Tampilan halaman login merupakan tampilan awal untuk menampilkan yang dimana pengguna harus meng-input 
username dan password terlebih dahulu sebelum mengakses aplikasi tersebut, terdapat dua pengguna pada sistem ini yaitu Admin dan Kasir. Data yang di-input harus sesuai pada database yang sudah tersimpan username dan password pengguna. Setelah terisi, tekan button Login yang tersedia pada tampilan, dan kemudian akan masuk ke halaman menu utama atau dashboard.

Tampilan sebelum masuk ke halaman menu utama adalah halaman Login. Berikut tampilan halaman Login:

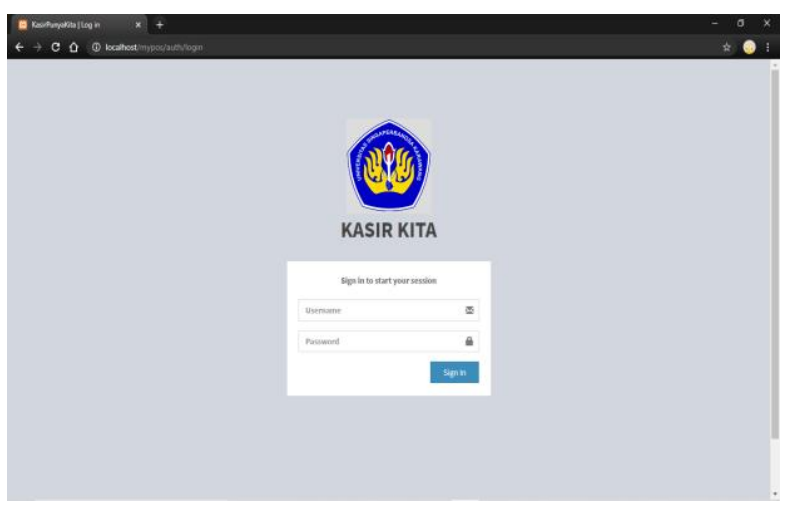

Gbr. 3 Tampilan Halaman Login

\section{B. Tampilan Halaman Dashboard}

Terdapat tujuh menu utama yang dapat diakses sebagai pengguna admin (Gambar 4). Pada bagian Dashboard terdapat 4 data menu, antara lain Items (terletak di menu Products), Supplier, Customer, dan Users. Maksud angka dari setiap menu tersebut merupakan data yang tersimpan di database dari setiap menu-menu tersebut. Menu Supplier berisi daftar pemasok barang yang bekerjasama dengan pemilik toko, di dalam menu supplier juga dapat menambahkan data pemasok barang yang baru.

Menu Customer (Pengguna) berisi daftar pelanggan yang tersimpan pada database, fungsi dari adanya Customer ini sebagai data bagi pelanggan tetap atau member yang berbelanja di sistem POS ini. Kemudian pada menu Products memiliki Submenu yang terdiri dari Categories yang berisi daftar kategori barang yang tersedia; Units yang berisi daftar satuan barang yang tersedia; dan Items yang berisi daftar barang yang telah disimpan ke Database dari pemasokpemasok barang.

Menu Transaction pun memiliki tiga submenu yaitu Sales berisi halaman formulir penjualan yang di halaman tersebut dilakukan transaksi antara kasir dengan pembeli; Stock in yang berisi halaman daftar data stok barang yang masuk dari pemasok barang atau supplier; Stock out yang berisi halaman data stok barang yang rusak, kadaluwarsa, ataupun hilang dari pemasok barang. Pada menu Reports berisi laporan penjualan atau aktifitas transaksi yang telah dilakukan oleh kasir. Menu Users, berisi daftar data pengguna yang telah disimpan pada Database.

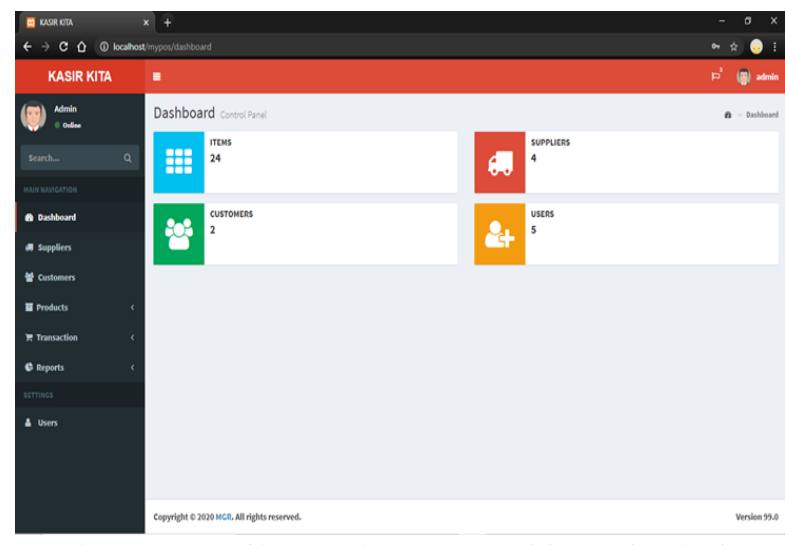

Gbr. 4 Tampilan Halaman Dashboard Admin

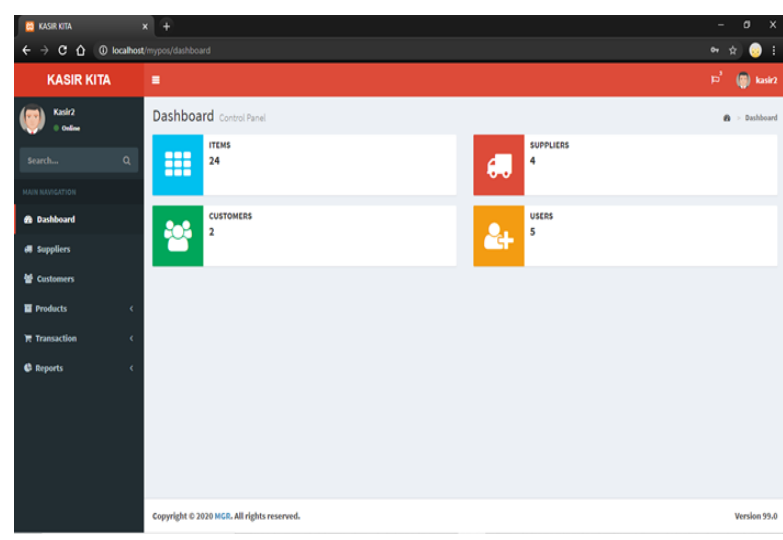

Gbr. 5 Tampilan Halaman Dashboard Kasir

Pada menu utama pengguna kasir, terlihat tidak memiliki akses ke menu Users, karena kasir tidak memiliki hak untuk merubah data dari pengguna yang tersimpan pada sistem ini. Pada menu Suppliers dan Customers, kasir hanya dapat melihat daftar data pemasok barang dan pelanggan yang tersimpan pada database yang artinya tidak memiliki hak untuk menambahkan data pemasok barang ataupun pelanggan ke database. Kemudian pada menu Transaction, kasir tidak memiliki hak untuk mengakses halaman Stock In karena sistem ini diatur agar hanya admin 
yang dapat menambahkan stok barang ke sistem POS.

\section{Tampilan Halaman Sales (Penjualan)}

Gambar 6 merupakan halaman menu transaksi penjualan, yang nantinya akan ada tampilan daftar barang yang di scan melalui scanner barcode. Menu ini dapat diakses oleh Admin dan Kasir, hanya saja tugas transaksi penjualan ini diserahkan ke Kasir.

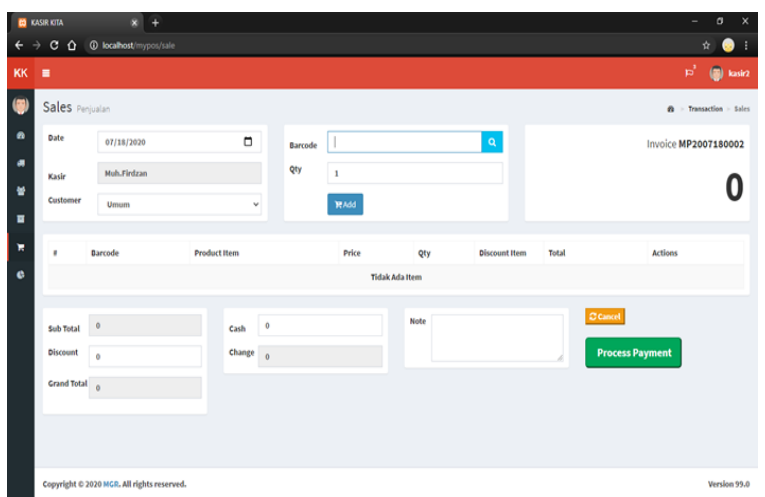

Gbr. 6 Tampilan Halaman Sales (Penjualan)

\section{Tampilan Halaman Stock In}

Gambar 7 merupakan halaman submenu Stock In yang terdapat pada menu Transaction, halaman ini hanya dapat diakses oleh pengguna admin. Menu Stock In ini bertujuan bila ada barang yang masuk dari pemasok barang, data barang yang masuk kemudian di input pada halaman formulir Stock In yang nantinya bila sudah tersimpan di database, stok barang yang berada di halaman Items atau data barang akan terupdate sesuai dengan stok yang dimasukkan pada halaman formulir Stock In.

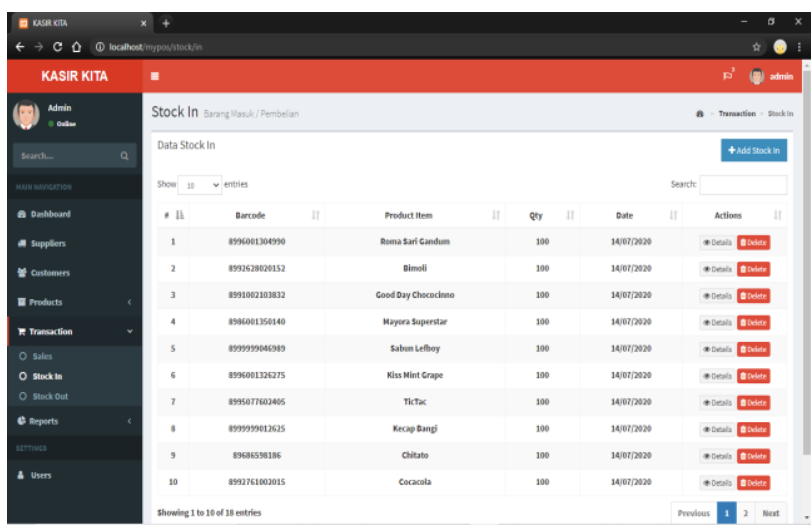

Gbr. 7 Tampilan Halaman Submenu Stock In

\section{E. Tampilan Halaman Stock Out}

Gambar 9 merupakan halaman Stock Out, yang juga dapat diakses oleh kedua pengguna. Halaman ini berisi data barang yang rusak atau hilang ataupun kadaluwarsa. Barang yang mengalami hal seperti itu, dapat diisi melalui formulir Stock Out yang telah disediakan Gambar 10. Kemudian stok barang yang ada pada submenu Items, akan terbaharui sesuai dengan barang yang diisi pada menu Stock Out.

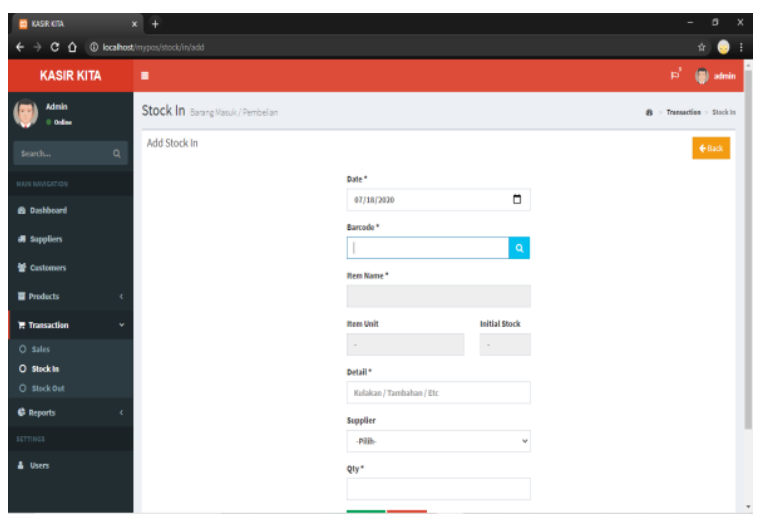

Gbr. 8 Tampilan Halaman Formulir Stock In

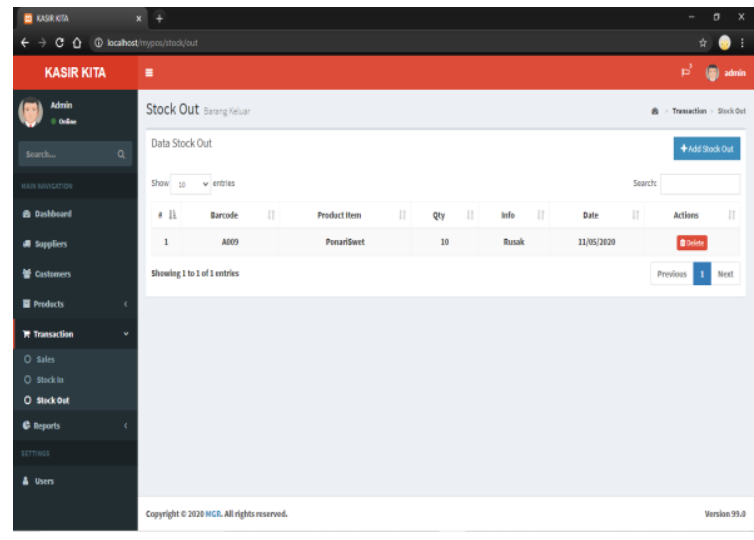

Gbr. 9 Tampilan Halaman Submenu Stock Out

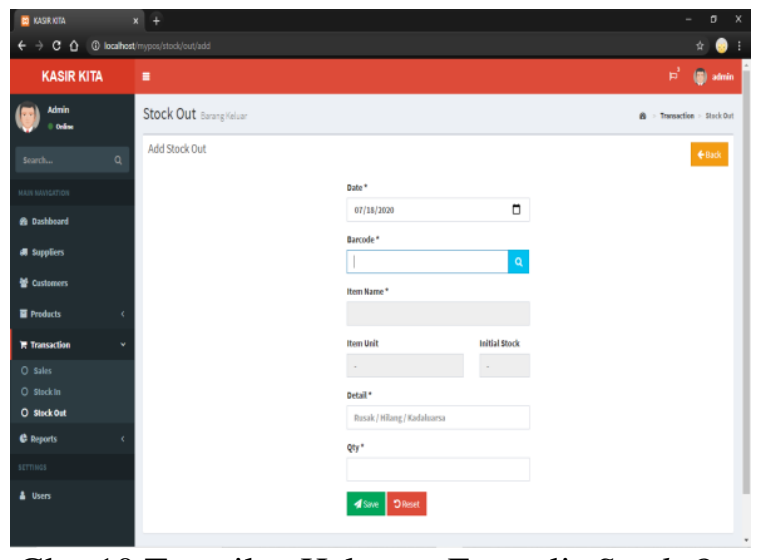

Gbr. 10 Tampilan Halaman Formulir Stock Out 


\section{F. Hasil Kuesioner}

Tabel 1. Hasil Kuesioner

\begin{tabular}{|c|c|c|c|c|c|c|c|}
\hline \multirow{2}{*}{ No } & \multirow{2}{*}{$\begin{array}{c}\text { Perta- } \\
\text { nyaan }\end{array}$} & \multicolumn{7}{|c|}{ Skor } & \multirow{2}{*}{ Total } \\
\cline { 3 - 8 } & Ke-1 & 3 & 4 & 4 & 0 & 0 & 11 \\
\hline 2 & Ke-2 & 2 & 7 & 2 & 0 & 0 & 11 \\
\hline 3 & Ke-3 & 1 & 7 & 3 & 0 & 0 & 11 \\
\hline 4 & Ke-4 & 2 & 6 & 3 & 0 & 0 & 11 \\
\hline 5 & Ke-5 & 3 & 7 & 1 & 0 & 0 & 11 \\
\hline 6 & Ke-6 & 3 & 5 & 3 & 0 & 0 & 11 \\
\hline 7 & Ke-7 & 1 & 6 & 4 & 0 & 0 & 11 \\
\hline 8 & Ke-8 & 3 & 7 & 1 & 0 & 0 & 11 \\
\hline 9 & Ke-9 & 3 & 7 & 1 & 0 & 0 & 11 \\
\hline 10 & Ke-10 & 3 & 7 & 1 & 0 & 0 & 11 \\
\hline Frekuensi & 24 & 63 & 23 & 0 & 0 & 110 \\
\hline $\begin{array}{r}\text { Persentase } \\
(\%)\end{array}$ & 21, & 57, & 20, & 0 & 0 & 100 \\
\hline
\end{tabular}

Keterangan:

SS = Sangat Setuju

$\mathrm{S}=$ Setuju

$\mathrm{N}=$ Netral

TS $=$ Tidak Setuju

STS $=$ Sangat Tidak Setuju

Kuesioner ini diberikan kepada 11 responden yang bekerja sebagai kasir/ operator pada pasar swalayan, dengan melontarkan 10 pertanyaan kepada pengguna kasir/ operator. Tujuan dari kuesioner ini adalah untuk mendapatkan tanggapan dari pengguna kasir terhadap sistem aplikasi POS yang sudah dibuat. Ditinjau dari Tabel 1, dapat diketahui semua responden menjawab semua pertanyaan yang diberikan. Total frekuensi 110 respon dari 11 respon dan 10 pertanyaan. Respon Sangat Setuju (SS) memiliki frekuensi 24 respon dan persentase yang didapat sebesar $21,82 \%$. Respon Setuju (S) memiliki frekuensi 63 respon dan persentase yang didapat sebesar $57,27 \%$. Respon Netral (N) memiliki 23 respon dan persentase sebesar $20,91 \%$.

Sedangkan respon Tidak Setuju (TS) dan Sangat Tidak Setuju (STS) sama sekali tidak memiliki respon. Berdasarkan hasil respon yang telah diperoleh, dapat disimpulkan bahwa sistem aplikasi POS ini user friendly atau mudah untuk dioperasikan oleh pengguna kasir ataupun operator.
G. Validasi

Tabel 2. Validasi Pengujian Sistem

\begin{tabular}{|c|c|c|c|}
\hline $\begin{array}{l}\mathbf{N} \\
\mathbf{0}\end{array}$ & Sistem Uji & Keterangan & $\begin{array}{l}\text { Kesim } \\
\text { pulan }\end{array}$ \\
\hline \multirow[b]{2}{*}{1} & \multirow{2}{*}{$\begin{array}{l}\text { Halaman } \\
\text { Sales }\end{array}$} & \begin{tabular}{l}
\multicolumn{2}{l}{ Meng-input } \\
barang sesuai \\
dengan barang \\
yang akan dibeli \\
tidak terjadi \\
kesalahan
\end{tabular} & Valid \\
\hline & & $\begin{array}{lr}\text { Perhitungan total } \\
\text { harga sebelum } \\
\text { diskon dan total } \\
\text { harga setelah } \\
\text { diskon tidak } \\
\text { terlihat adanya } \\
\text { kesalahan }\end{array}$ & Valid \\
\hline 2 & $\begin{array}{l}\text { Halaman } \\
\text { Items } \\
\text { (Data } \\
\text { Barang) }\end{array}$ & $\begin{array}{l}\text { Data stok barang } \\
\text { awal (sebelum } \\
\text { transaksi) } \\
\text { berkurang setelah } \\
\text { dilakukan } \\
\text { transaksi } \\
\text { pembelian sesuai } \\
\text { dengan jumlah } \\
\text { barang yang } \\
\text { dibeli dan tidak } \\
\text { terjadi kesalahan }\end{array}$ & Valid \\
\hline 3 & $\begin{array}{l}\text { Halaman } \\
\text { Percetakan } \\
\text { Nota }\end{array}$ & $\begin{array}{lr}\text { Halaman } & \text { Nota } \\
\text { otomatis } & \text { muncul } \\
\text { ke halaman yang } \\
\text { baru } & \text { sesuai } \\
\text { dengan } & \text { program } \\
\text { sistem } & \text { yang } \\
\text { dibuat } & \\
\end{array}$ & Valid \\
\hline
\end{tabular}

Validasi adalah suatu ukuran yang menunjukkan hasil dari rancangan sistem yang telah di uji dalam proses pengujian. Data diambil dengan melakukan pengujian sistem untuk mencari tahu apakah sistem ini berjalan dengan baik atau tidak.

Hasil pengujian data (Tabel 2) yang sudah dilakukan sesuai dengan program sistem yang telah dirancang. Pengujian yang dilakukan berdasarkan proses dalam transaksi penjualan. Proses-proses sistem yang telah diuji menghasilkan data yang valid, tidak terjadinya kesalahan sistem pada program POS ini. 


\section{PENUTUP}

Berdasarkan hasil analisis data dan pembahasan dapat disimpulkan bahwa respon Sangat Setuju (SS) memiliki frekuensi 24 respon dan persentase yang didapat sebesar 21,82\%. Respon Setuju (S) memiliki frekuensi 63 respon dan persentase yang didapat sebesar 57,27\%. Respon Netral (N) memiliki 23 respon dan persentase sebesar 20,91\%. Sedangkan respon Tidak Setuju (TS) dan Sangat Tidak Setuju (STS) sama sekali tidak memiliki respon. Berdasarkan hasil respon yang telah diperoleh, dapat disimpulkan bahwa sistem aplikasi POS ini user friendly atau mudah untuk dioperasikan oleh pengguna kasir ataupun operator.

Agar sistem ini berkembang lebih baik lagi, penulis memberikan saran menambahkan fitur laporan penjualan skala per hari, per minggu, per bulan, hingga per tahun agar memudahkan pengguna dalam membuat laporan dan mengurangi kesalahan human error saat membuat laporan penjualan, menambahkan fitur pembayaran dengan $e$ money seperti Gopay, Dana, PayPal dan lain sebagainya serta menambahkan fitur multi customer yang berfungsi agar dapat melakukan transaksi penjualan dengan 2 atau lebih pelanggan yang sedang memasukkan barang ke dalam Trolley.

\section{REFERENSI}

[1] A. Kadir, Pengenalan Sistem Informasi edisi Revisi. Yogyakarta: Andi, 2003.

[2] S.E, Tommy, Membuat Sistem Aplikasi Minimarket (Point of Sales) dengan VB \& MYSQL 5. Jakarta: Elex MediaKomputindo, 2008.

[3] L. Al-Bahra Bin, Analisis dan Desain Sistem Informasi. Yogyakarta: Graha Ilmu, 2005.

[4] S. Dian, H. Permana, F. Telematika, U. Trilogi, and U. M. Language, "Analisa dan Perancangan Aplikasi Point Of Sale (Pos) Untuk Mendukung Manajemen Hubungan Pelanggan," Vol. 2, No. 1, Pp. 20-28, 2015.

[5] J. Sugihartono et al., "Pembuatan Aplikasi," vol. 3, no. 4, pp. 445-455, 2015.
[6] S. Rahayu, Zuriati, and D. Sahlinal, "Aplikasi Point of Sale Berbasis Web Menggunakan Framework Codeignitier Pada Martabak Abc," Progr. Stud.Manaj. Inform., p. 2, 2017.

[7] A. Prayitno and Y. Safitri, "Pemanfaatan Sistem Informasi Perpustakaan Digital Berbasis Website Untuk Para Penulis," Indones. J. Softw. Eng., vol. 1-1, no. 1, 2015. 